\title{
Maternal alpha-fetoprotein screening: two years' experience in a low-risk district
}

\author{
SUSAN J STANDING, M J BRINDLE, A P MACDONALD, R W LACEY
}

\begin{abstract}
Over a two-year period, 3479 pregnant women in the King's Lynn Health District were screened for neural tube defects by estimation of maternal serum $\alpha$-fetoprotein. Most pregnancies were scanned by sonar for fetal maturity. Eight women had fetuses with open neural tube defects; four with anencephaly were associated with very high $\alpha$-fetoprotein values. Of the four with open neural tube defects without anencephaly, only one was detected by screening and confirmed after amniocentesis. One other had a raised serum $\alpha$-fetoprotein but a normal amniotic ffuid value. The other two affected fetuses were missed. This disappointing outcome was attributed to the poor predictive value of $\alpha$-fetoprotein in detecting open neural tube defects (anencephaly apart) rather than to errors in its estimation or in assessment of fetal maturity by sonar scan. We question the validity of screening, particularly in areas of intermediate or low incidence.
\end{abstract}

\section{Introduction}

The incidence of malformations of the central nervous system (as recorded in 1977) varies from 3.9 per 1000 in Wales to $2 \cdot 6$ per 1000 in East Anglia. ${ }^{1}$ Screening the serum of pregnant

\footnotetext{
Departments of Pathology, Diagnostic Imaging, and Obstetrics, Queen Elizabeth Hospital, King's Lynn, Norfolk

SUSAN J STANDING, BSC, FIMLS, chief medical laboratory scientific officer

M J BRINDLE, MD, MRAD, consultant radiologist

A P MACDONALD, FRCOG, consultant in obstetrics and gynaecology

R W LACEY, MD, MRCPATH, consultant chemical pathologist
}

women at $16-18$ weeks' gestation for $\alpha$-fetoprotein can result in the detection of about $80 \%$ of fetuses with open neural tube deiects. ${ }^{2} 3$ The hazards of such screening, however, include maternal anxiety and the fetal mortality associated with amniocentesis (probably $1-1.5 \%$ ). ${ }^{4}$

In the past two years we have routinely screened pregnant women for serum $\alpha$-fetoprotein in a district where the incidence of neural tube defects is relatively low, and we describe our results. We believe our experience casts doubt on the desirability of screening maternal serum for $\alpha$-fetoprotein.

\section{Patients and methods}

The King's Lynn Health District provides maternity services for a population of about 170000 . Over $98 \%$ of the 2200 births a year are in hospital. About $31 \%$ of women are delivered in a peripheral maternity unit and the rest at the district general hospital, where supporting services are based. During pregnancy over $95 \%$ of women are supervised jointly by consultants and general practitioners; fewer than $5 \%$ are monitored by general practitioners alone. Referral to hospital usually occurs between the ninth and sixteenth week of gestation. Each patient referred to the district general hospital has a sonar scan at her first visit. Patients attending the peripheral antenatal clinic do not have a routine scan.

For two years, from 1 April 1978 to 31 March 1980, all pregnant women presenting before 19 weeks' gestation were offered screening for serum $x$-fetoprotein, but only $80 \%$ of pregnancies were screened, largely because of late presentation. About $75 \%$ of the patients screened underwent a sonar scan and clinical examination at the same time as the blood sample was taken.

Sonar was performed with a Diasonagraph 4102B machine by one of two radiographers specially trained. The accuracy of maturity estimation by scanning was determined by an analysis of 98 consecutive patients from this series, who were sure of the date of the last menstrual period and who went into labour spontaneously. The gestational age was estimated using the crown rump length ${ }^{5}$ in those patients presenting sufficiently early and the biparietal diameter ${ }^{6}$ in the remainder. 


\section{$\alpha$-FETOPROTEIN ESTIMATION}

$\alpha$-Fetoprotein was measured by radioimmunoassay using the Abbott AFP RIA diagnostic kit. Thorough internal and external quality assessment was undertaken. With few exceptions, assays were performed in batches at intervals of a week or less. Within-batch variation for patient samples was $5 \cdot 4 \%$ and the between-batch variation was $7-11 \%$. After venepuncture, serum samples were stored at $-15 \mathrm{C}$ pending assay. The normal range was established initially by assaying samples in parallel with St Bartholomew's Hospital. Results were generally expressed as multiples of the median at either $15,16,17,18$, or 19 weeks. When the clinical estimate of the duration of gestation differed from that given by scan, the latter figure was used to calculate the multiplicity of the median. Results at, or greater than, $2 \times$ median were reported as possibly abnormal. After exclusion of multiple pregnancy or incorrect dating, a repeat sample was requested as soon as possible.

Of the 3479 patients screened over the two years, 77 had one repeat sample assayed and three had presented early enough to allow time for two repeats. Forty-five amniocenteses were performed (these included 15 patients who did not have repeat serum $\alpha$-fetoprotein assayed because of either insufficient time or because amniocentesis was indicated by other factors such as maternal age). Amniotic $\alpha$-fetoprotein concentrations were measured at the Regional Cytogenetics Unit, Fisherton Street, Salisbury, or the Centre for Human Genetics, 117 Manchester Road, Sheffield.

\section{Results}

The figure shows an analysis of the sample of 98 consecutive patients sure of the date of their last menstrual period examined by sonar before 16 weeks who went into labour spontaneously: 77 delivered within nine days of the date estimated from the crown-rump length or biparietal diameter.

During the two years of the study 121 women of the 3479 screened

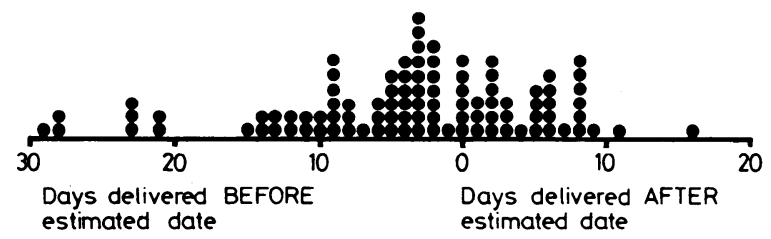

Difference between sonar estimation and actual date of delivery in 98 consecutive patients who went into labour spontaneously.
TABLE I-Outcome of borderline and raised $\alpha$-fetoprotein results in 121 patients

Normal babies delivered

Singletons

Twins

Missed / spontan

Anencephalics

netions

Open detected

Other ab

Chromosome 2 abi. . .

Raised maternal serum $\alpha$-fetoprotein not supported by amniotic fluid concentration, therefore not terminated

concentration, therefore

Open neural tube defect

Spontaneurs abortion

Raised maternal serum $\alpha$-fetoprotein twice, amniocentesis not successful,

ultrasound ?abnormal, terminated

The termination of the pregnancy in the one patient found to have a fetus with a severe neural tube defect was the only major positive benefit from the screening programme. In the three instances where a raised serum $x$-fetoprotein was not supported by raised amniotic fluid $x$-fetoprotein the patients were not offered termination of pregnancy (table II). One patient aborted spontaneously after amniocentesis, another delivered a live infant with an open neural tube defect, and the fourth gave birth to a child with a closed defect. In the patient in whom amniocentesis was unsuccessful repeat serum $\alpha$-fetoprotein was $210 \mu \mathrm{g} / \mathrm{l}$ (about $4 \times$ median). A fetal abnormality appeared likely and vaginal bleeding persisted. Termination was carried out at 22 weeks by last menstrual period and a fetus with recent maceration delivered. There was no obvious fetal abnormality, specifically no oesophageal atresia, nephrosis, or neural tube defect.

Three patients with normal serum $\alpha$-fetoprotein concentrations (and who therefore did not have amniocentesis) gave birth to babies with severe neural tube defects (two open and one extensive closed defect associated with hydrocephaly) (table III). All of these died at, or shortly after, birth. Two of the abnormal babies were identified by ultrasound late in pregnancy, but the third was not examined. We did not expect to detect the closed defect, and in practice the failure to detect the open lesions did not affect the final outcome. Nevertheless, all could have survived.

\section{Discussion}

During the two-year period eight women became pregnant with babies with severe open neural tube defects, including

TABLE II-Patients with abnormal $\alpha$-fetoprotein values

\begin{tabular}{|c|c|c|c|c|c|}
\hline $\begin{array}{l}\text { Patient } \\
\text { No }\end{array}$ & Age & Parity & $\begin{array}{c}\text { Serum } \alpha \text {-fetoprotein } \\
(\mu \mathrm{g} 1)\end{array}$ & $\begin{array}{l}\text { Amniotic fluid } \\
\text { x-fetoprotein } \\
\text { (mg l })\end{array}$ & Outcome \\
\hline 1 & 30 & $3+0$ & \multirow{4}{*}{$\begin{aligned} & 101(4.0 \times \text { median }) \\
& \text { repeat } 183(6.0 \times \text { median }) 169(6.0 \times \text { median }) \\
& 169 \text { repeat } 150(4.5 \times \text { median }) \\
& 134(3.6 \times \text { median }) \\
& \text { repeat } 140(3.9 \times \text { median }) \\
& 101(2.7 \times \text { median })\end{aligned}$} & 160 & Vaginal termination of fetus with open \\
\hline 2 & 32 & $4+0$ & & 25 (normal) & Spontaneous abortion of normal fetus three \\
\hline 3 & 25 & $0+0$ & & 23 (normal) & $\begin{array}{l}\text { Normal labour; girl with open neural tube } \\
\text { defect }\end{array}$ \\
\hline 4 & 31 & $1+0$ & & 19 (normal) & Normal delivery girl with closed \\
\hline 5 & 21 & $1+0$ & $\begin{array}{r}240(4.9 \times \text { median }) \\
\text { repeat } 210(4.0 \times \text { median })\end{array}$ & $\begin{array}{l}\text { Amniocentesis } \\
\text { failed }\end{array}$ & Termination of apparently normal fetus \\
\hline
\end{tabular}

had $\alpha$-fetoprotein concentrations greater than $2 \times$ median (table I). Normal singleton babies and twins accounted for 99. Twenty-two pregnancies remained. In 14 there was clear evidence of a severe abnormality, associated with missed or spontaneous abortion in 10 and anencephaly in four. Of the eight remaining, three fetuses were found to have chromosome abnormalities and one had an open neural tube defect; in three cases the raised serum $\alpha$-fetoprotein was not supported by the concentration found in the amniotic fluid, and in one, amniocentesis was unsuccessful.

In the four cases of ancencephaly the maternal serum $\alpha$-fetoprotein concentration was greater than $5.0 \times$ median. Three were already suspected because of their appearance on scan, but the fourth was diagnosed after a repeat scan when the high concentration of $\alpha$-fetoprotein was known.
TABLE III-Patients with normal $\alpha$-fetoprotein and abnormal fetuses

\begin{tabular}{|c|c|c|c|c|}
\hline $\begin{array}{l}\text { Patient } \\
\text { No }\end{array}$ & Age & Parity & $\begin{aligned} \text { Serum } & \alpha \text {-fetoprotein } \\
& (\mu \mathrm{g} 1)\end{aligned}$ & Outcome \\
\hline 6 & 19 & $1+0$ & $\begin{array}{r}71(2.1 \times \text { median }) \\
\text { repeat } 73(2.0 \times \text { median })\end{array}$ & $\begin{array}{l}\text { Delivery at } 37 \text { weeks } \\
\text { of infant with closed } \\
\text { ocipital } \\
\text { meningocoele }\end{array}$ \\
\hline 7 & 26 & $2+0$ & $68(18 \times$ median $)$ & $\begin{array}{l}\text { Stillborn infant } \\
\text { delivered at } 37 \\
\text { weeks with open } \\
\text { meningomyelocoele }\end{array}$ \\
\hline 8 & 34 & $3+0$ & $68(1.6 \cdot$ median $)$ & $\begin{array}{l}\text { Caesarean section at } 36 \\
\text { weeks; girl with } \\
\text { open neural tube } \\
\text { defect }\end{array}$ \\
\hline
\end{tabular}


four with anencephaly-an incidence of $2 \cdot 3$ per thousand births, which is typical in East Anglia. Of those with open neural tube defects, apart from anencephaly, the programme detected one fetus with a lesion that was confirmed by amniotic fluid $x$-fetoprotein, detected one that was not confirmed in this way, and missed two.

This screening programme was instigated with the expectation that it would prevent the birth of most live babies with open neural tube defects. After two years these expectations had not been fulfilled and, with the agreement of all those connected with the maternity service, the screening programme was discontinued.

Our disappointing results are probably not due to poor precision or accuracy of our $\boldsymbol{x}$-fetoprotein assay, nor due to atypical errors with scanning. Our main difficulty was that interpretation of the serum $\alpha$-fetoprotein concentration is critically dependent on the estimated gestational age. An error of one week in the estimate of maturity-for example, at 16 weeks-causes an alteration in the calculated multiple of the median of about $15^{\prime \prime}$. Accuracy of the estimation could be improved by earlier presentation at the clinic and by the use of newer scanners.

There were inevitable difficulties in getting samples and correct details, particularly those concerning gestation, to the laboratory and in returning results to the clinic in sufficient time to influence immediate management. Awaiting results, especially on repeat samples, caused concern to both patients and medical staff. Some problems of communication were experienced between this district and reference laboratories performing amniotic $\alpha$-fetoprotein assays, but this did not influence the outcome of any pregnancy in this series.

We believe that the correlation between concentrations of maternal serum $x$-fetoprotein and fetal open neural tube defects, anencephaly apart, is insufficiently close to justify this type of screening, certainly in parts of the country with a relatively low incidence of neural tube defects. Other similar hospitals, particularly in central and eastern England, should consider carefully whether to embark on, or to continue such a programme. A clear benefit to the patient or community, or both, should be apparent to justify screening because, cost and labour apart, many patients experienced considerable anxiety, particularly the relatively high number who required more than one serum estimation. Moreover, even if the screen was more specific for open neural tube defects, it might still preferentially detect fetuses that would perish spontaneously.

We thank Mr G Reynolds for performing the scans, Mrs R Philipson for taking blood, Mrs J Cooper for typing the manuscript, and Miss S Macaskill and Mr A B W Taylor for permission to review their patients.

\section{References}

1 Working Group on Screening for Neural Tube Defects. Report. London DHSS, 1979.

2 Brock DJH, Scrimgeour JB, Steven J, Barron L, Watt M. Maternal plasma alpha-fetoprotein screening for fetal neural tube defects. $B r \mathcal{F}$ Obitet Gynaecol 1978;85:575-81.

3 Wald NJ, Cuckle HS. Alphafetoprotein in the antenatal diagnosis of open neural tube defects. Br 7 Hosp Med 1980;23:473-89.

${ }^{4}$ Medical Research Council Working Party on Amniocentesis. An assessment of the hazards of amniocentesis. Br F Obstet Gynaecol 1978;85 suppl 2:1-41.

"Robinson HP, Fleming JEE. A critical evaluation of sonar "crown rump length" measurements. Br f Obstet Gynaecol 1975;82:702-10.

6 Campbell S. An improved method of fetal cephalometry by ultrasound. Fournal of ()bstetrics and Gynaecology of the British Commonwealth 1968 75:568-76.

(Accepted 8 fuly 1981)

\title{
An investigation into the management of bilateral leg amputees
}

\author{
CATHERINE M C VAN DE VEN
}

\begin{abstract}
Patients with bilateral high level amputations of the legs are rarely func ${ }^{\prime}$ ionally independent after their discharge from hospital. Eighty bilateral amputees were visited by a research physiotherapist, and information was obtained on their family circumstances, accommodation, mobility, and prostheses. A second questionnaire was completed by hospital staff on medical condition, assessments, rehabilitation, and total overall management.

The results showed that mobility was severely restricted; out of the 80 patients visited, only 65 could manoeuvre wheelchairs and 23 use prostheses. Accommodation presented difficulties: 34 homes had steps inside and 40 had steps outside. Of the 80 patients seen, 60 could not cope in the bath while 33 were unable to use the lavatory. Assessments and rehabilitation were lacking. There appeared to be little overall management, and hospital staff made only 36 visits to the patient's accommodation before discharge.
\end{abstract}

Queen Mary's Hospital and DHSS Limb Fitting Centre, London SW15 5PR

CATHERINE M C, VAN DE VEN, MCSP, superintendent physiotherapist

\section{Introduction}

About 5000 new patients with leg amputations are referred to the DHSS artificial limb and appliance centres each year. Of these, around $3500(70 \%)$ are over 60 , and $3750(75 \%)$ have lost their limbs through peripheral vascular disease or diabetes. ${ }^{1}$ Some $450(9 \%)$ of these new amputees have lost both legs; in half these cases the patients have had one leg amputated earlier, losing the remaining leg because of systemic disease. ${ }^{2}$

These figures do not include amputees who are not referred to limb fitting centres. Of the 100 amputees in this project, seven patients had never been to an artificial limb and appliance centre or a limb fitting centre.

Management of elderly amputees suffering from systemic diseases is often complicated by associated medical problems, such as hemiparesis and shortness of breath from heart or lung disease. $^{34}$ The problems are worse when the individual has a bilateral amputation, and the higher the level of amputation the more difficult and complicated the rehabilitation. ${ }^{5}$

To be of any use help must be realistic and within each patient's physical and mental capabilities. Independence in selfcare such as dressing, bathing, and using the lavatory has to be relearnt because of new physical circumstances, ${ }^{6}$ and patients and their families need to make many readjustments. ${ }^{7}$ 